\title{
INFLUENCE OF REEF FLAT SUBMERGENCE ON INFRA- GRAVITY WAVE ENERGY AND RESONANCE OVER THE FRINGING REEF
}

\author{
Pham Lan Anh* \\ Thuyloi University, No 175 Tay Son Street, Hanoi, Vietnam
}

\author{
ARTICLE INFO \\ TYPE: Research Article \\ Received: 5/10/2020 \\ Revised: 30/10/2020 \\ Accepted: 6/11/2020 \\ Published online: 25/01/2021 \\ https://doi.org/10.47869/tcsj.72.1.3 \\ * Corresponding author \\ Email: lananhct@tlu.edu.vn; Tel: 0989979584
}

\begin{abstract}
Fringing reefs which are common nearshore islands with coral reef growth have a special topography of very steep slope on the fore-reef and mild slope on the wide flat. When the incident waves propagate from a very deep water region (from hundreds of meters to thousands of meters of depth) to approaching the reef they abruptly commence a very shallow water (only few centimeters to several meters of depth) and create strong hydrodynamic processes on the reef flat. Due to shallow depth, the waves feel the bottom and break in the area of fore-reef slope and reef crest and partial reef flat. Infra-gravity waves (IG), other name as bound long waves or surf beat, which belong to low-frequency wave type $(0.002 \mathrm{~Hz} \div$ $0.04 \mathrm{~Hz})$ are generated by the varying-breaking point mechanism on the shallow reef flat. On the flat, short wave energy is almost dissipated; low-frequency waves are strongly dominated over the surf zone till swash zone. Wave set-up causing an increase of water level on the flat combines with the run-up at the shoreline which can lead to coastal flooding. Besides, if the reef flat length is in the order of one fourth of wavelength the first oscillation resonant mode with standing wave occurs. This component is resonantly amplified at the shoreline relative to the incident infra-gravity wave energy at the reef crest.
\end{abstract}

Keywords: Infra-gravity waves, fringing reefs, natural resonance, standing waves, submerged depth, wave setup 


\section{INTRODUCTION}

In Vietnam, most nearshore tropical islands are coral reefs growth. Amongst which some are ranked fringing reefs with special topography such as: Truong Sa Lon, Son Ca, Song Tu Tay... Reality has seen many destructive failures in costal structure of these low-lying regions due to strong wave impact, coastal flooding, wave overtopping... Coastal flooding could be originated from several reasons, one of which is due to infra-gravity resonance at the shoreline causing high variability of water level. For port operation wave resonance prevents the usual service of vessels entrance and mooring.

In deep water, incident wave energy is dominated by wind-generated sea swell (SS) waves which has peak period that typically ranging from 5-25s. In the nearshore fringing reef, depth-limited wave breaking can result in water level variability at the shoreline that is dominated by infra-gravity waves (IG) with period greater than 25s (Guza \& Thornton, 1982). Infra-gravity waves born off-shore of the surf zone due to variation in radiation stress gradient (Longuet-Higgins \& Stewart 1962) is usually forced to bound the SS wave groups with very low frequency or in other word, long period and propagate shoreward with the SS wave group. The so-called "bound long waves" is the other name of this type of IG waves generated by this mechanism. Once short wave energy dissipates via turbulence or heat in the surf zone, previously generated bound long waves can be released as free waves. However, IG waves are also generated by the cross-shore movement of SS breakpoint associated with waves varying heights in a group breaking in different water depths (Symonds et al, 1982). Bound waves release is considered to be an important source of free IG waves at a gentle sloping beach (Jassen 2003), whereas breaking point forcing has been shown to dominate IG waves on steep beaches (Baldock 2012). For a fringing reef with abrupt variation in bathymetry and extremely steep fore reef slope, the main mechanism of IG waves generation is certainly the varying breakpoint of SS wave groups.

The oscillation of water surface occurs when infra-gravity energy spectrum peaks at the natural frequency of the reef flat. Incoming infra-gravity waves once reach the back reef could be reflected to create standing waves $\left(\mathrm{R}^{2}=\mathrm{H}_{\mathrm{s}, \mathrm{r}}^{2} / \mathrm{H}_{\mathrm{s}, \mathrm{i}}^{2} \gg 0.5\right.$; R- the reflection coefficient; $\mathrm{H}^{2}{ }_{\mathrm{s}, \mathrm{r}^{-}}$reflected wave height; $\mathrm{H}_{\mathrm{s}, \mathrm{i}}^{2}$ - incident wave height). If standing wave nodes coincide with the reef crest position ( $x=0$ in Fig.1) infra-gravity waves might be excited to resonant amplification frequency; normally it happens in case the reef flat length is $\mathrm{N}$ fold of one fourth of infra-gravity wavelength $(\mathrm{N}=0,1,2, .$.$) (Nwogu 2010). Buckley et al. (2016,2018)$ demonstrated the strong presence of infra-gravity resonance between two typical reef morphology: with bottom roughness and without bottom roughness. Recently, Chen (2019), Yao et al. (2019) confirmed the possibility of low-frequency amplification for smooth reef, rough-bed reef and reef with lagoon. However, relative submerged depth which plays a vital role in modifying the shoreline wave resonance has not been mentioned yet. This study goal is therefore to go in-depth in influence of submerged depth on infra-gravity wave and resonance over fringing reef.

\section{EXPERIMENTAL SETUP}

The physical model was conducted in the $45 \mathrm{~m}$ long $1.2 \mathrm{~m}$ high and $1.0 \mathrm{~m}$ wide wave flume of Thuy Loi University, Hanoi, Vietnam. The piston wave type generator is equipped with the active reflection compensation system (AUKEPC/ARC-DELTARES) to ensure wave reflection removal at the wave maker and create irregular wave height up to $0.3 \mathrm{~m}$ and $3.0 \mathrm{~s}$ in 
peaks. Wave gauges is based on capacitance principle and measure with $\pm 0.1 \mathrm{~mm}$ accuracy. Velocity measurement is placed on several positions combined with the wave measurement to estimate bulk head reflection coefficients.

The idealized reef model was designed to mimic the typical fringing reef geometry with steep fore reef slope and almost flat reef platform based on the consideration of different reef geometry dimensions. Water depth in front of the reef foot is in order of hundreds of meters meanwhile on the flat it is in the range from more than $1 \mathrm{~m}$ to $4 \mathrm{~m}$. The transitional section from deep water to shallow water could vary from a very steep deep foot (slope steepness $1 / 3$ ) to a milder slope $(1 / 5-1 / 10)$. The reef flat length could change due to different wave propagation direction (North, North East, East, South East, West, South West, North West, South). Because of constraints in space arrangement it could not model all the practical fringing reef dimension into the wave flume; only important part of the fringing reef relating to the wave transformation process is considered. Then a length scaled model of 1:40 was chosen to fully describe the test wave condition. Effect of reef roughness is neglected in the experiment as it is not the main topic of study and hardly to model at small scale. Fig. 1 illustrates the experiment arrangement and fringing reef model dimension. The reef surface is coated by smooth cement grout elevated $0.5 \mathrm{~m}$ to the flume bed to insure generation of deep water waves. The horizontal flat length is $10 \mathrm{~m}$ (400m in prototype); fore reef slope steepness is 1:5 and the back reef slope steepness is 1:5 and extended to the top of flume to ensure non wave overtopping. Whole reef is located $22 \mathrm{~m}$ from the wave maker.

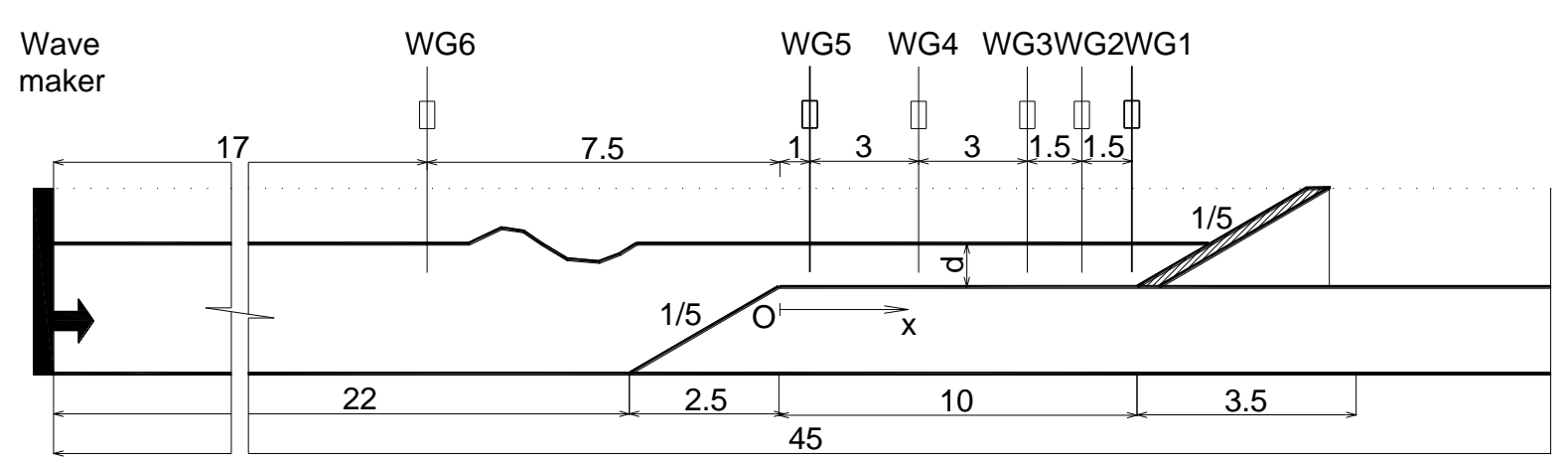

Fig. 1. Experimental set up and wave gauge locations.

Six wave gauges are installed in the model with suitable spacing to determine surf zone and post breaking zone. In order to measure waves at low surface water elevation on the reef flat, five holes are drilled into the reef surface so that wave gauge (WG1-WG5) can be lowered inside the hole. WG6 measures deep water wave condition distancing $17 \mathrm{~m}$ from the wave maker. The sampling rate frequency is set at $50 \mathrm{~Hz}$ for all wave gauges. The experiment scenario is described in Table 1 consisting 18 test cases with 3 varying water levels. Wave environment around East Sea of Viet Nam depends the monsoon season and become extremely robust during tropical storm. JONSWAP spectra with the peak enhancement factor $\gamma=1.25$ is found to be the most suitable to Viet Nam storm wave condition in East Sea with tested wave heights $(0.03 \mathrm{~m}-0.15 \mathrm{~m})$ and periods $(1.0 \mathrm{~s}-1.6 \mathrm{~s})$ 
Transport and Communications Science Journal, Vol. 72, Issue 1 (01/2021), 16-24

Table 1. Experiment scenarios.

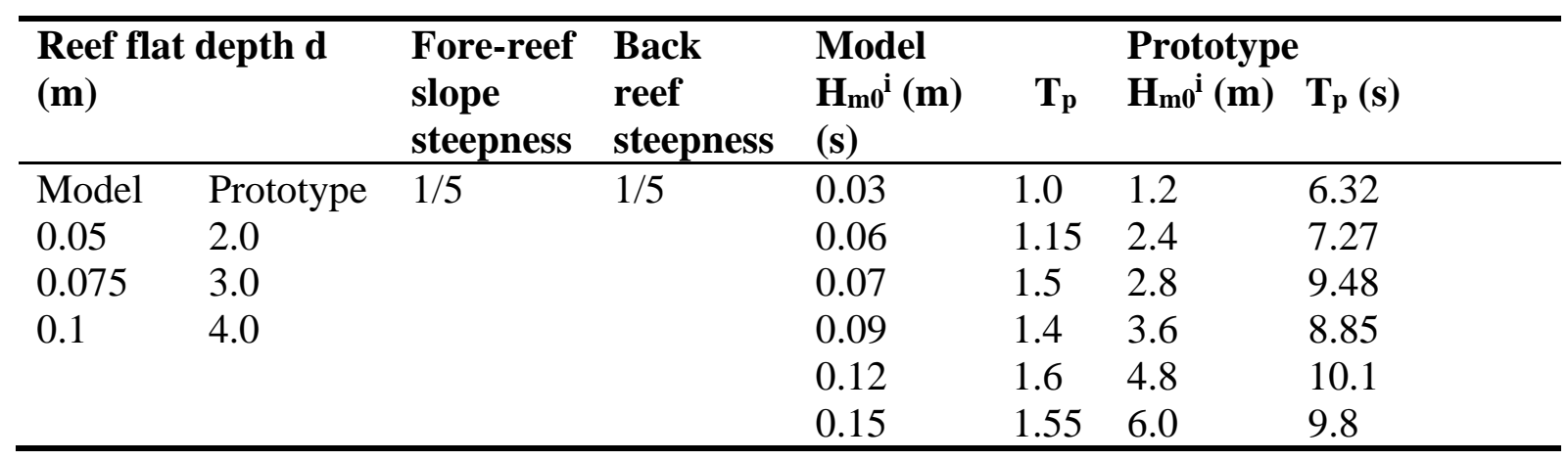

\section{RESULTS AND DISCUSSION}

\subsection{Surface elevation time series}
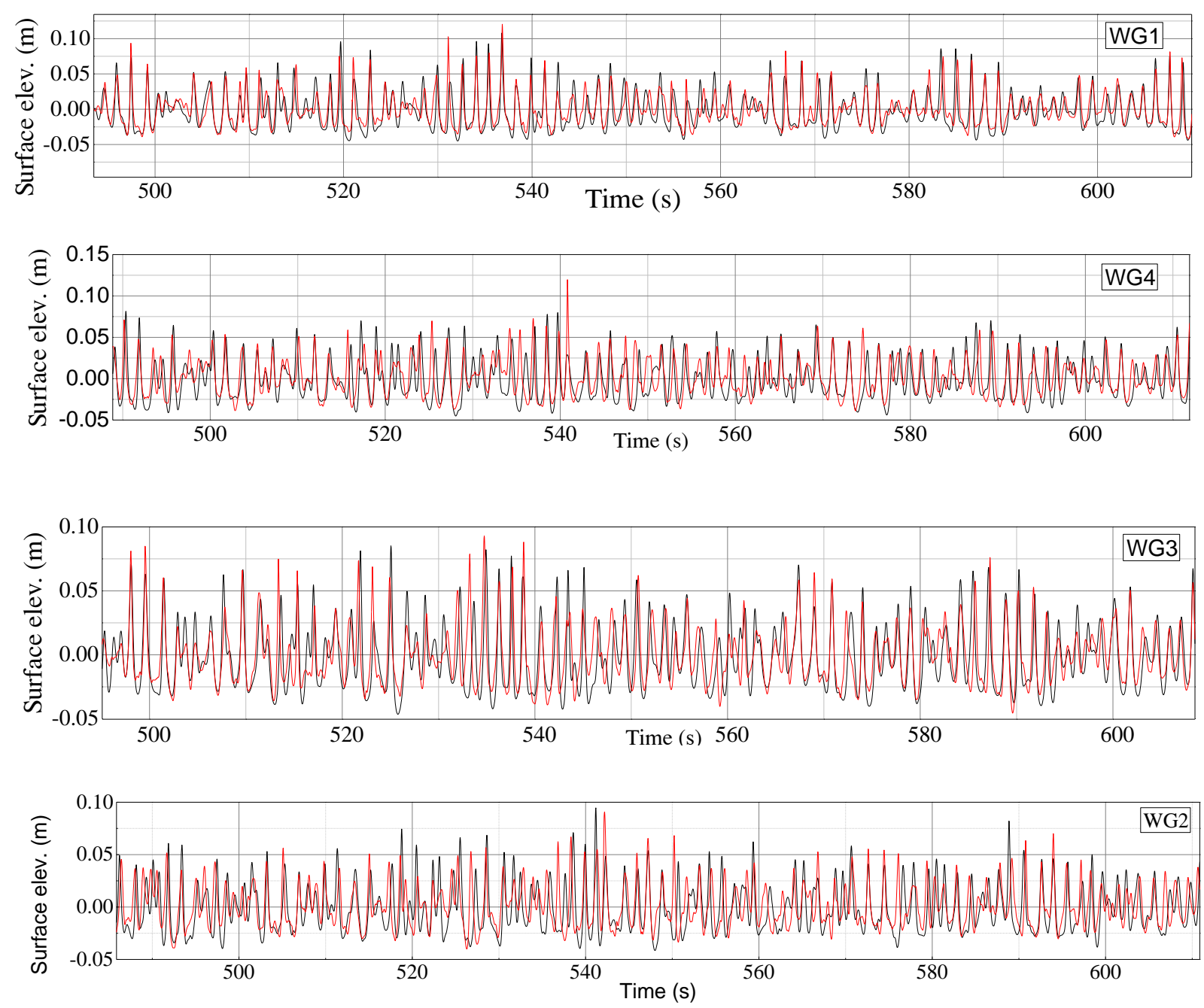

Fig 2. Measured and calculated surface water elevation time series under $d=0.05 \mathrm{~m}, \mathrm{H}_{\mathrm{mo}}=0.09 \mathrm{~m}, \mathrm{~T}_{\mathrm{p}}=$ $1.4 \mathrm{~s} ;$ measure in red, swash numerical model in black.

Results of experiment are shown in form of surface water elevation time series over six gauges. Swash 1D model using shallow water equation (Zijlema 2012) was set up to validate 
Transport and Communications Science Journal, Vol. 72, Issue 1 (01/2021), 16-24

experimental data set Fig 2. Measured surface water elevation is well coincided to calculated surface water elevation with the breaking coefficient $\mathrm{C}_{\mathrm{br}}=0.2$ and the friction coefficient $\mathrm{C}_{\mathrm{f}}=$ 0.015 in Swash under $\mathrm{d}=0.05 \mathrm{~m}, \mathrm{H}_{\mathrm{mo}}=0.09 \mathrm{~m}, \mathrm{~T}_{\mathrm{p}}=1.4 \mathrm{~s}$. In general, there is a minimal phase lag between numerical model and the measured data, however, the error estimator is within 5\% which is totally acceptable (Pham Lan Anh 2020). In Fig 2, gauge 1 which is at the foot of back reef and gauge 4 which is in the post breaking zone present peaks that exceeds $0.10 \mathrm{~m}$; other gauges over reef flat shows water surface fluctuation with smaller amplitude. Hence these peaks were analysed to consider resonance occurrence due to the first two modes.

\subsection{Wave energy spectrum transformation}

Experiment data set provide the time series of surface elevation at six gauges across the reef. Based on Fast Fourier Transform wave energy spectrum obtained from time series.
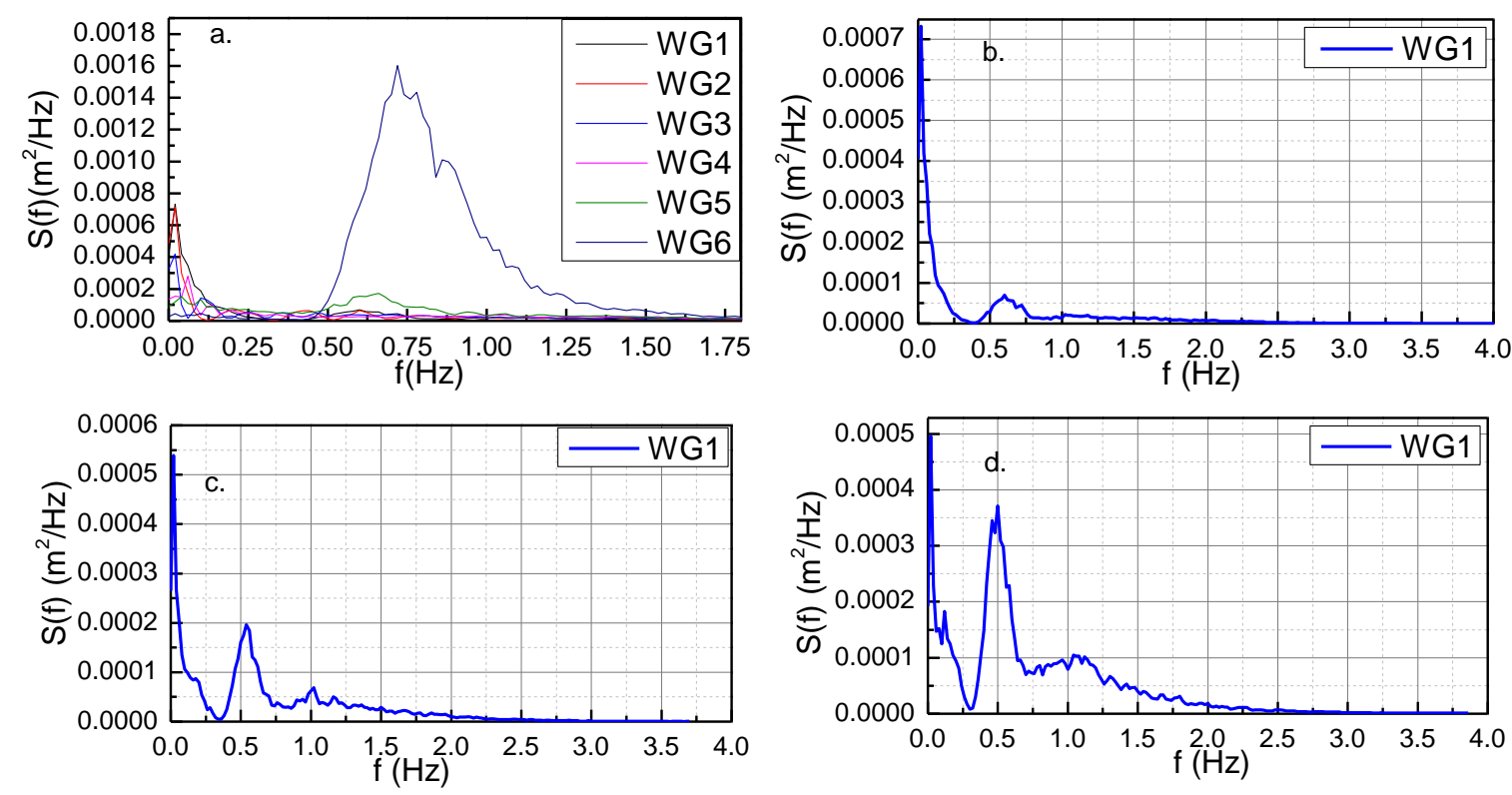

Fig. 3. Wave spectral transformation under $\mathrm{H}_{\mathrm{mo}}=0.09 \mathrm{~m}, \mathrm{~T}_{\mathrm{p}}=1.4 \mathrm{~s} ; \mathrm{a}$. Wave spectra at 6 gauges under $\mathrm{d}=0.05 \mathrm{~m}$; $\mathrm{b}$. Wave spectra at WG1 under $\mathrm{d}=0.05 \mathrm{~m}$; . Wave spectra at WG1 under $\mathrm{d}=0.075 \mathrm{~m}$; $\mathrm{d}$.

Wave spectra at WG1 under $\mathrm{d}=0.1 \mathrm{~m}$.

Wave spectra is divided into short wave-high frequency $\left(f>f_{c}\right)$ and IG wave - low frequency $\left(f \leq f_{c}\right)$ relied on the demarcating frequency $f_{c}$, where $f_{c}=0.5 f_{p}$ and $f_{p}$ is the peak frequency of the incident wave. It can be seen from fig 3a. that wave energy largely dissipates at the reef edge (WG6, WG5) and remains relatively unchanged after the surf zone (WG4, WG3). Most of incoming short waves break near fore reef slope and partly in the beginning of reef crest due to shoaling effect. WG6 located in deep water region which was to obtain incident deep water wave has typical profound spectrum shape of short waves. When propagating shoreward, the peak becomes flat (WG5, WG4) demonstrating dissipation of short wave energy. After the breaking zone, another peak at low frequency is formed demonstrating the generation of infra-gravity wave (WG3, WG2, WG1) on the reef flat and it 
increases all the way from the reef crest to shoreline. The further waves propagate shoreward, the more robust the infra-gravity wave energy.

Short wave energy with higher frequency ( $\mathrm{f}>0.36 \mathrm{~Hz}$ in model $/ 0.05 \mathrm{~Hz}$ in field scale) has transferred back to long wave energy with lower frequency $(\mathrm{f} \leq 0.36 \mathrm{~Hz})$ which is shown by the shifted peaks moving backward to left axis. This explains the generation of infra-gravity waves (IG) due to the time varying breaking point (Symond et al. 1982) and domination of low frequency wave on the reef flat. Figure $3 b, 3 c, 3 d$ shows the dependence of energy dissipation on the submerged depth $d$ which is denoted in fig. 1. For the same incident wave height and period, short wave energy dissipation rate decrease and IG wave energy decreases when submerged depth increases. For $\mathrm{d}=0.1 \mathrm{~m}$, short wave energy peaks highest amongst three water depths; the one for $\mathrm{d}=0.075$ ranks second and the smallest peak energy is for $\mathrm{d}=0.05 \mathrm{~m}$. In contrast, IG wave energy peaks highest for $\mathrm{d}=0.05 \mathrm{~m}$ and smallest for $\mathrm{d}=0.1 \mathrm{~m}$.

This could be clearly explained by introducing the relative submerged depth $\mathrm{d} / \mathrm{H}_{\mathrm{mo}}{ }^{\mathrm{i}}$ which significantly effects on the concentration of low frequency energy $\left(\mathrm{H}_{\mathrm{mo}}\right.$ i incident moment spectra wave height). Figure $4 \mathrm{~d}$. represents the variation of moment spectrum wave height $\left(\mathrm{H}_{\mathrm{IG}}, \mathrm{H}_{\mathrm{SS}}\right)$ due to relative submerged depth. $\mathrm{H}_{\mathrm{IG}}$ (moment IG spectrum wave height), $\mathrm{H}_{\mathrm{SS}}$ (moment spectrum short wave height) are estimated from the energy wave spectra, $\mathrm{S}(\mathrm{f})$ as

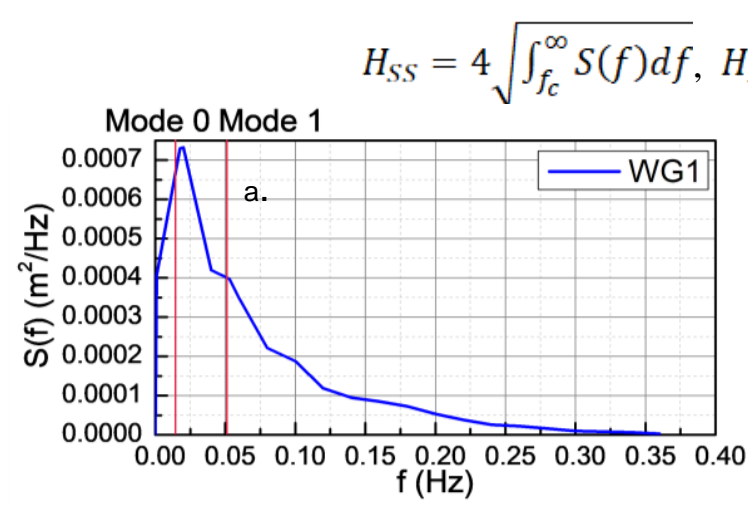

$$
H_{I G}=4 \sqrt{\int_{0}^{f_{c}} S(f) d f}
$$
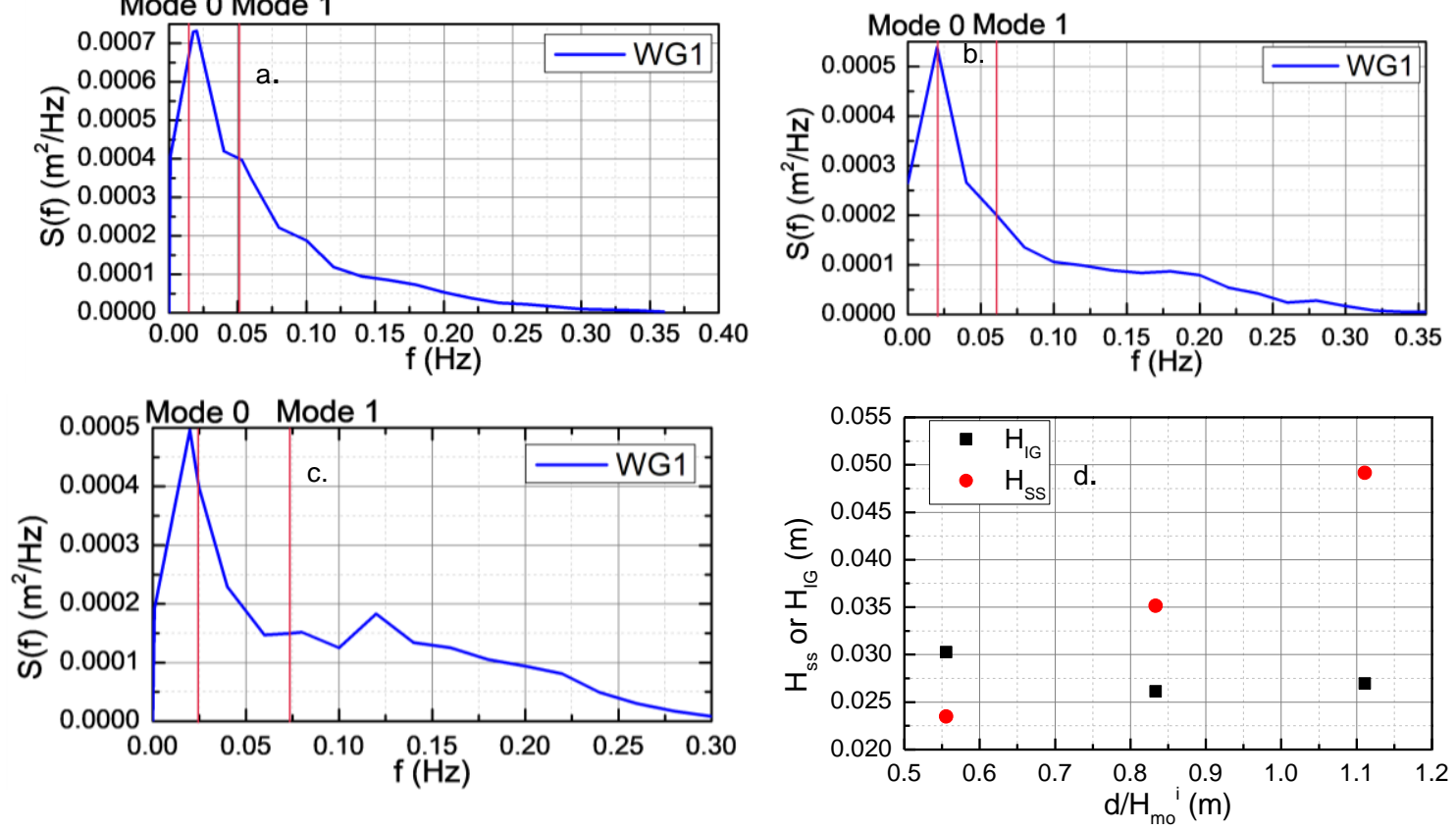

Fig.4. a. Wave spectra (WG1) within the IG band under $d=0.05 \mathrm{~m}$; b. Wave spectra (WG1) within the IG band under $\mathrm{d}=0.075 \mathrm{~m}$; c. Wave spectra (WG1) within the IG band under $\mathrm{d}=0.1 \mathrm{~m}$; $\mathrm{d}$. Short wave height $\mathrm{H}_{\mathrm{ss}}$ (red) and IG wave height (black) with respect to relative water depth. Vertical red line: the first two modal frequencies of the reef resonance. Wave condition $\mathrm{H}_{\mathrm{mo}}=0.09 \mathrm{~m}, \mathrm{~T}_{\mathrm{p}}=1.4 \mathrm{~s}$

If the ratio $\mathrm{d} / \mathrm{H}_{\mathrm{mo}}{ }^{\mathrm{i}}$ decreases (the water depth is smaller than the characteristic height of incident waves) all most all incoming wave energy dissipates due to breaking; the transferring 
from high frequency wave energy to low frequency wave energy become stronger; IG wave frequency band intensifies and gets higher peak spectrum. Corresponding to the spectrum transformation, it is shown in fig. $3 d$ that $H_{I G}$ goes down, whereas $H_{s s}$ goes up once $d / H_{m o}{ }^{i}$ increase. For depth submergence $\mathrm{d}=0.05$ gives the $\mathrm{H}_{\mathrm{ss}}$ two third of $\mathrm{H}_{\mathrm{IG}}$ value.

\subsection{Infra-gravity wave resonance}

Fringing reef profile has been generally considered as an open basin that supports resonance modes of oscillation. The natural resonance frequency can be estimated by

$$
T_{n}=\frac{4 l_{r}}{(2 n+1) \sqrt{g(d+\eta)}} ; n=0,1,2,3 \ldots
$$

In which, $T_{n}$ is the resonance period of the N-th mode, $l_{r}$ is the reef-flat length, $\mathrm{d}$ is reef flat submergence and $\eta$ is the wave setup on the reef flat, $g$ is the gravity acceleration. To further investigate the response of IG waves near the shoreline (WG1), wave spectra within IG wave frequency band width is extracted by low pass filter. Three submerged water depths used to compare the natural frequency excitation under incident wave condition $\mathrm{H}_{\mathrm{mo}}{ }^{\mathrm{i}}=0.09 \mathrm{~m}$, $\mathrm{T}_{\mathrm{p}}=1.4 \mathrm{~s}$. The first two fundamental resonance modes are the most common ones amongst four natural modes. The first mode $(n=0)$ and the second mode $(n=1)$ have nodes at the shoreline and anti-nodes at the reef crest with $1 / 4$ and $3 / 4$ of IG wave length which equals the reef flat length respectively. Formula (2) points out the natural resonance period is inversely proportional to the submerged water depth. Hence, in fig. $4 a, 4 b, 4 c$ the vertical red line represents varies with different depth submergence. For mode 0 the excited frequencies are $0.018,0.022,0.026$ for $\mathrm{d}=0.05,0.075$ and $0.1 \mathrm{~m}$ respectively. For mode 1 the excited frequencies are $0.054,0.066,0.076$ for $\mathrm{d}=0.05,0.075$ and $0.1 \mathrm{~m}$ respectively. It can be seen from fig. $3 a$ and $3 b$ that mode 0 is excited for two submerged depth $d=0.05$ and $d=0.075 \mathrm{~m}$ according to peak spectrum coincides to the red line. Mode 0 has node occurring at the reef crest and anti-node at the shoreline with flat length equalling one fourth of IG wave length. For $\mathrm{d}=0.1 \mathrm{~m}$ the peak happens near resonance frequency for both two modes. It seems that less resonant IG wave energy is excited for this water depth, hence, water surface oscillation at the shore line under $\mathrm{d}=0.1 \mathrm{~m}$ is less robust than the others.
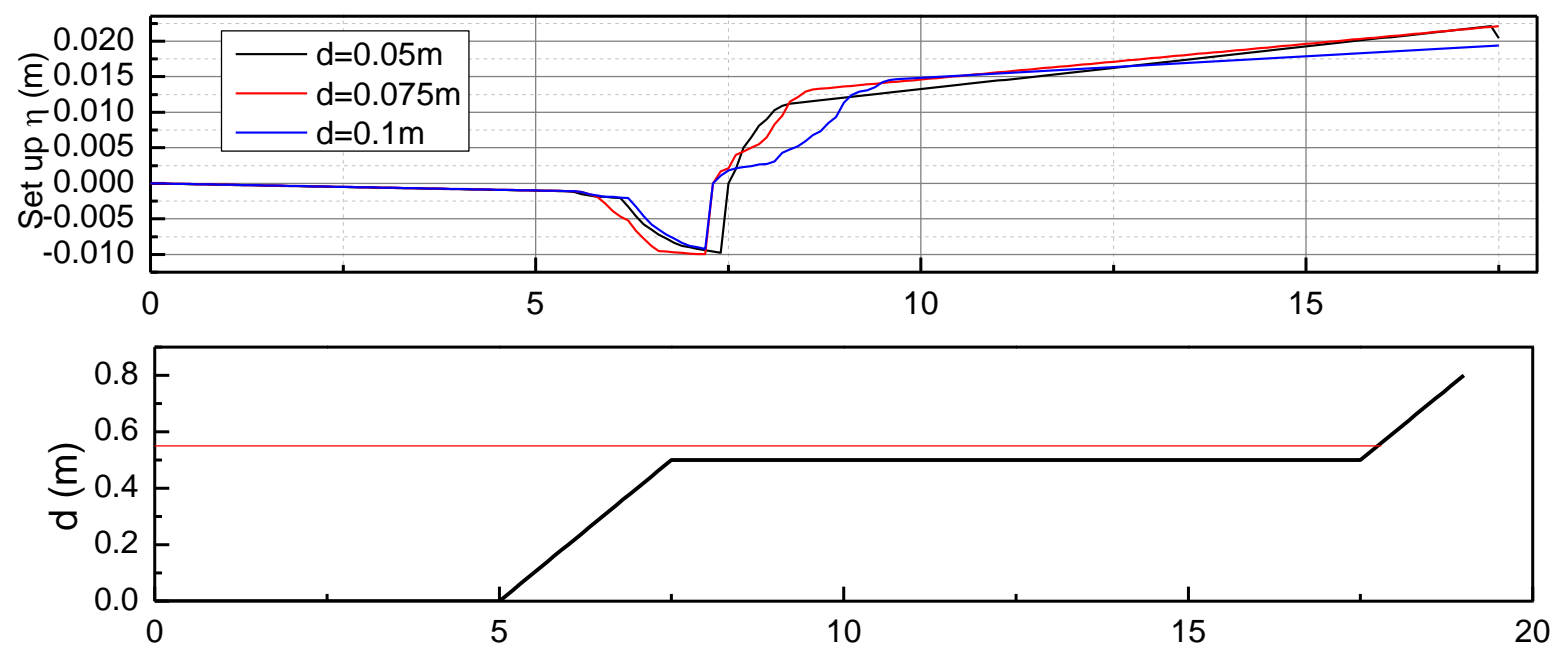

Fig. 5. Wave set-up across the reef flat; Wave condition $H_{m o}=0.09 m, T_{p}=1.4 \mathrm{~s}$. 
Fig. 5 is the estimated wave set-up across the reef flat in case resonance amplification and near resonance happens. There is a similar trend in setup for all three levels. At the shoreline depth $d=0.1 \mathrm{~m}$ sounds increase slightly meanwhile depth $\mathrm{d}=0.05 \mathrm{~m}$ and $0.075 \mathrm{~m}$ the increase rate is rather faster which represents strong shoreline amplification.

\section{RESULTS AND DISCUSSION}

Laboratory experiment was carried out to investigate the influence of submerged depth $d$ on IG wave energy transformation as well as IG wave resonance at the shoreline. Within the scope of this paper, only the most relevant results amongst 18 tests are presented in order to demonstrate the depth submergence dependence.

From experiment results, it can be concluded that the relative submergence $d / \mathrm{H}_{\mathrm{mo}}{ }^{\mathrm{i}}$ significantly effects IG wave energy generation and wave resonance. Low relative submergence supports waver energy transfer from high to low frequency and the highest IG wave energy peak obtained at the smallest $\mathrm{d} / \mathrm{H}_{\mathrm{mo}}{ }^{\mathrm{i}}$ amongst the three water depth.

Resonant mode 0 clearly happens for two submergence $d=0.05$ and $d=0.075 \mathrm{~m}$ (corresponding to $2 \mathrm{~m}$ and $3 \mathrm{~m}$ in prototype) under $10 \mathrm{~m}$ flat length (400m in prototype) with the amplified period in the order of $45 \mathrm{~s}$ to $55 \mathrm{~s}$ in model scale corresponding to $285 \mathrm{~s}$ to $355 \mathrm{~s}$ in field scale respectively. Once again it is emphasized that low relative submergence helps wave resonance better than higher ones.

In fact, there are still several factors affecting the amplified frequency such as reef flat length, the incident wave height and the capability of back reef reflection to create standing waves that have not mentioned in this paper. Further studies should be carried out to investigate carefully the problem.

\section{ACKNOWLEDGMENT}

This experiment research is facilitated by Thuyloi university and partly funded by the Thuyloi Scientific research fund.

\section{REFERENCES}

[1]. T. E. Baldock, Dissipation of incident forced long waves in the surf zone-Implications for the concept of "bound" wave release at short wave breaking, Coastal Engineering, 60 (2012) 276-285. https://doi.org/10.1016/j.coastaleng.2011.11.002

[2]. M. Buckley et al., Wave setup over a fringing reef with large bottom roughness, Journal of Physical Oceanography, 46 (2016) 2317-2333. https://doi.org/10.1175/JPO-D-15-0148.1

[3]. M. Buckley et al., Mechanisms of wave-driven water level variability on Reef-fringed coastlines, Journal of Geophysical Research: Oceans, $123 \quad$ (2018) 3811-3831. https://doi.org/10.1029/2018JC013933

[4]. R. T. Guza, E. B. Thornton, Swash oscillations on a natural beach, Journal of Geophysical Research, 87 (1982) 483-491. https://doi.org/10.1029/JC087iC01p00483

[5]. T. T. Janssen, J. A. Battjes, A. Van Dongeren, Long waves induced by short-wave groups over a sloping bottom, Journal of Geophysical Research, 108 (2003) 3252. https://doi.org/10.1029/2002JC001515

[6]. M. S. Longuet-Higgins, R. W. Stewart, Radiation stress and mass transport in gravity waves, with 
Transport and Communications Science Journal, Vol. 72, Issue 1 (01/2021), 16-24

application to 'surf beats. Journal of Fluid Mechanics, 13 (1962) 481-504. https://doi.org/10.1017/S0022112062000877

[7]. H. Chen et al., Evolution of irregular wave shape over a fringing reef flat, Ocean engineering, 192 (2019) 106544. https://doi.org/10.1016/j.oceaneng.2019.106544

[8]. O. Nwogu et al., Infragravity wave motions and runup over shallow fringing reefs, Journal of Waterway, Port, Coastal, and Ocean Engineering, $136 \quad$ (2010) 295-305. https://doi.org/10.1061/(ASCE)WW.1943-5460.0000050

[9]. M. Zijlema, Modelling wave transformation across a fringing reef using swash, Coastal Engineering Proceedings, 33 (2012) 1-12. https://doi.org/10.9753/icce.v33.currents.26

[10]. Y. Yao et al., Effects of reef morphology variation on wave processes over fringing reefs, Applied ocean research, 82 (2019) 52-62. https://doi.org/10.1016/j.apor.2018.10.021

[11]. G. Symonds et al., Two-dimensional surf beat: Long wave generation by a time-varying breakpoint, Journal of Geophysical Research, 87 (1982) 492-498. https://doi.org/10.1029/JC087iC01p00492

[12]. Pham Lan Anh, Validation of experiment data set over fringing reef by Swash 1D Proceedings of the annual conference of Thuyloi university, 2020. 